\title{
Gambaran Acute Physiologic and Chronic Health Evaluation (APACHE) II, Lama Perawatan, dan Luaran Pasien di Ruang Perawatan Intensif Rumah Sakit Umum Pusat Dr. Hasan Sadikin Bandung pada Tahun 2017
}

\author{
Bramantyo Pamugar, ${ }^{1}$ Erwin Pradian, ${ }^{2}$ Iwan Fuadi ${ }^{2}$ \\ ${ }^{1}$ Bagian Anestesi RSUD Encik Mariyam, Riau, ${ }^{2}$ Departemen Anestesiologi dan Terapi Intensif \\ Fakultas Kedokteran Universitas Padjadjaran/RSUP Dr. Hasan Sadikin Bandung
}

\begin{abstract}
Abstrak
Skor acute physiologic and chronic health evaluation (APACHE) II, lama perawatan, dan luaran pasien merupakan indikator penting di Intensive Care Unit (ICU). Ketiga indikator ini dapat berbeda dari satu dengan tempat lain. Ketiga indikator ini dapat dibandingkan di tempat lain untuk meningkatkan pelayanan ICU. Tujuan penelitian ini adalah mengetahui gambaran skor APACHE II, lama perawatan, dan angka mortalitas pada pasien yang dirawat di ICU RSUP Dr. Hasan Sadikin Bandung pada tahun 2017. Metode yang digunakan adalah deskriptif observasional yang dilakukan secara retrospektif terhadap 303 objek penelitian. Objek penelitian diambil di bagian rekam medis pada bulan April 2018. Penelitian ini memperoleh hasil skor APACHE II berkisar 0-56 dengan rerata 16,68, angka mortalitas sebesar 130 (42,3\%), dan lama perawatan berkisar 2-79 hari dengan rerata 9,89 hari. Data skor APACHE II terhadap angka kematian berbeda dengan Amerika Serikat yang dapat dikarenakan perbedaan acuan prediksi mortalitas, underestimation derajat keparahan pasien cedera kepala, bias yang disebabkan oleh penatalaksanaan pasien pre-ICU, dan satu waktu pemeriksaan skor APACHE II.
\end{abstract}

Kata kunci: APACHE II, ICU, lama perawatan, luaran pasien

\section{Overview of Acute Physiologic and Chronic Health Evaluation (APACHE) II, Length of Stay, and Patient Outcome in the Intensive Care Unit of Dr. Hasan Sadikin General Hospital in 2017}

\begin{abstract}
The APACHE II score, length of stay, and patient outcome are important indicators in Intensive Care Unit (ICU). Those indicators could be different from one place to another and can be compared to increase the quality of health services in ICU. The purpose of this study was to describe acute physiologic and chronic health evaluation (APACHE) II, length of stay, and mortality rate of patients at the ICU of Dr. Hasan Sadikin General Hospital Bandung from January 1 to December 31, 2017. This was a retrospective descriptive observational study on 303 patient medical records. It was revealed that the APACHE score was ranging from 0-56 (mean $=16.68)$; the mortality rate was $42.9 \%(n=130)$; and the length of stay was 2-79 days (mean 9.89 days). This suggests a gap in these indicators between Dr. Hasan Sadikin General Hospital and hospitals in the United States of America which may be due to differences in the the standard that is used to predict the mortality rate, underestimation of severity of head injury, treatment before admission to ICU, and single time assessment of APACHE II.
\end{abstract}

Key words: APACHE II, ICU, length of stay, outcome

Korespondensi: Bramantyo Pamugar, dr., SpAn, Bagian Anestesi RSUD Encik Mariyam, Riau, Jl. Masjid Sultan 46, Daik, Lingga, Kep. Riau 29871, Tlpn. 08192253037,Email artz.gar@gmail.com 


\section{Pendahuluan}

Sistem skor penyakit kritis merupakan penilaian derajat keparahan penyakit berdasar atas data-data spesifik yang diambil ketika perawatan. Sistem skor penyakit kritis juga dapat memprediksi angka mortalitas dalam rumah sakit. Sistem skor ini telah berkembang dalam tiga puluh tahun terakhir di ICU. ${ }^{1}$

Skor acute physiology and chronic health evaluation (APACHE) II merupakan salah satu skor penilaian penyakit kritis yang banyak dipakai di ICU yang berdasar pada nilai-nilai objektif fisiologis dari variabel-variabel yang diukur selama perawatan. Skor ini merupakan model yang baik dalam menentukan prediksi mortalitas dalam rumah sakit. Skor APACHE II memberikan gambaran keadaan pasien sebelum masuk ICU dan juga memberikan gambaran luaran pasien dan lama perawatan. Penilaian APACHE II dilakukan dalam kurun waktu 24 jam pertama di ICU. ${ }^{1-3}$

Lama perawatan di ICU merupakan salah satu indikator penting dalam penilaian efektivitas pelayanan ICU dan bermanfaat untuk memberikan gambaran kebutuhan sumber daya, tenaga kerja, dan biaya yang diperlukan di ICU. Peningkatan lama perawatan berhubungan dengan peningkatan risiko infeksi, komplikasi, angka mortalitas, serta beban biaya dan beban mental pasien, keluarga dan juga rumah sakit. Indikator lama perawatan pasien dapat memberikan gambaran performa ICU. ${ }^{4,5}$

Skor APACHE II, luaran, dan lama perawatan adalah indikator yang penting pada pelayanan kesehatan di ICU. Skor APACHE II dapat menggambarkan keadaan pasien sebelum masuk ICU. Luaran dan lama perawatan dapat menunjukkan performa ICU. Gambaran skor APACHE II, luaran, dan lama perawatan di daerah lain, serta di waktu lain dapat berbeda. Hal ini perlu dibandingkan untuk peningkatan pelayanan di ICU.

Tujuan penelitian ini adalah memberikan gambaran skor APACHE II, lama perawatan, dan luaran pasien yang dirawat di ICU RSUP Dr. Hasan Sadikin Bandung pada tahun 2017.

\section{Subjek dan Metode}

Penelitian ini menggunakan data sekunder dengan metode deskriptif retrospektif. Variabel-variabel yang diperlukan diambil melalui catatan rekam medis. Data-data yang diambil adalah seluruh pasien dengan usia $\geq 18$ tahun yang keluar dari ICU RSUP Dr. Hasan Sadikin Bandung periode 1 Januari hingga 31 Desember 2017. Data pasien yang tidak lengkap, pasien yang meninggal $\leq 24$ jam, dan pasien yang pulang atas keinginan sendiri dieksklusi dari penelitian.

Peneliti melakukan pengambilan data melalui bagian rekam medis di RSHS Bandung setelah mendapatkan persetujuan dari Komite Etik Penelitian Kesehatan Fakultas Kedokteran Universitas Padjadjaran/RSUP Dr. Hasan Sadikin Bandung. Penelitian ini dilakukan di bulan April 2018.

Data dikumpulkan menggunakan lembar penilaian penelitian yang berisi variabelvariabel yang sudah terukur yang diperlukan dalam penelitian. Lembar penelitian ini diawasi oleh tim pembimbing dan disertakan di lampiran (editing). Data dalam lembar penelitian dikonversi ke bentuk angka dan dikelompokkan agar mudah diukur dan diolah (coding). Data yang telah diedit dan diberi kode diolah menggunakan program statistical product and service solution (SPSS) versi 24.0 for windows, yaitu program pengolahan data statistik (data entry).

Pengecekan kembali dilakukan setelah semua data dimasukkan ke dalam program SPSS. Tujuannya adalah agar data yang digunakan tetap lengkap sebelum diolah dan dianalisis karena akan memengaruhi hasil analisis

Data hasil observasi rekam medis dikelompokkan sesuai dengan definisi operasional variabel penelitian. Data ini dianalisis secara deskriptif dengan bantuan aplikasi komputer. Data hasil penelitian dianalisis dan disajikan dalam bentuk tabel dan grafik sesuai dengan variabel yang diidentifikasi selama penelitian. 


\section{Hasil}

Jumlah pasien setelah melewati kriteria inklusi dan eksklusi adalah 303. Subjek dengan kelompok usia terbanyak adalah 18 hingga 64 tahun dengan jenis kelamin terbanyak adalah laki-laki, dengan indikasi masuk ICU terbanyak adalah indikasi bedah, dan luaran yang terbanyak adalah pasien yang pindah ruangan (Tabel 1).

\section{Tabel 1 Karakteristik Umum Pasien}

\begin{tabular}{|c|c|}
\hline Data Umum & Jumlah \\
\hline \multicolumn{2}{|l|}{ Usia (tahun) } \\
\hline $18-65$ & $242(79,9 \%)$ \\
\hline$>65$ & $61(20,1 \%)$ \\
\hline \multicolumn{2}{|l|}{ Jenis kelamin } \\
\hline Pria & $164(54,1 \%)$ \\
\hline Wanita & $139(45,9 \%)$ \\
\hline \multicolumn{2}{|l|}{ Indikasi masuk ICU } \\
\hline Nonbedah & $88(29,1 \%)$ \\
\hline Bedah & $215(70,9 \%)$ \\
\hline Digestif & $59(27,4 \%)$ \\
\hline Trauma & $9(4,1 \%)$ \\
\hline B. saraf & $41(19,1 \%)$ \\
\hline Obstetri-Ginekologi & $41(19,1 \%)$ \\
\hline Onkologi & $7(3,2 \%)$ \\
\hline Ortopedi & $13(6,0 \%)$ \\
\hline Toraks-vaskular & $27(12,6 \%)$ \\
\hline B. plastik & $9(4,1 \%)$ \\
\hline Lain-lain & $9(4,1 \%)$ \\
\hline \multicolumn{2}{|l|}{ Skor APACHE II } \\
\hline $0-4$ & $7(2,3 \%)$ \\
\hline $5-9$ & $39(12,9 \%)$ \\
\hline $10-14$ & $73(24,1 \%)$ \\
\hline $15-19$ & $77(25,4 \%)$ \\
\hline $20-24$ & $65(21,5 \%)$ \\
\hline $25-29$ & $25(8,3 \%)$ \\
\hline $30-34$ & $15(5,0 \%)$ \\
\hline$>34$ & $2(0,7 \%)$ \\
\hline \multicolumn{2}{|l|}{ Luaran } \\
\hline Pindah ruangan & $173(57,1 \%)$ \\
\hline Meninggal & $130(42,9 \%)$ \\
\hline
\end{tabular}

Skor rerata skor APACHE II pasien di ICU RSUP Dr. Hasan Sadikin Bandung tahun 2017 masih tinggi, yaitu 16,68 dengan rerata skor APACHE II pasien meninggal 19,69 dan pasien pindah ruangan 14,42 (Tabel 2).

Lama perawatan atas pasien di ICU RSUP Dr. Hasan Sadikin Bandung tahun 2017 adalah 9,89 hari dengan rerata lama perawatan pasien meninggal 9,33 hari dan pasien pindah ruangan 10,68 hari (Tabel 3).

Peneliti juga menemukan data lain yang dapat menunjang data di atas. Data lain ini juga dapat bermanfaat dalam meningkatkan pelayanan di ICU RSUP Dr. Hasan Sadikin Bandung. Data lain itu adalah: gambaran angka mortalitas ICU RSUP Dr. Hasan Sadikin Bandung dengan skor APACHE II, gambaran skor APACHE II dengan asal admisi, dan gambaran skor APACHE II dengan lama perawatan.

Semakin tinggi skor APACHE II maka angka mortalitas akan meningkat. Kelompok interval 0-4 mempunyai mortalitas $0,0 \%$. Peningkatan mortalitas terjadi seiring peningkatan skor APACHE II. Kelompok interval >34 mempunyai mortalitas $100 \%$ (Tabel 4).

Skor APACHE II pasien yang masuk ICU yang berasal dari emergensi adalah 17,91. Skor tersebut sedikit lebih tinggi dibanding dengan skor APACHE II pasien yang berasal dari ruang rawat, yaitu 16,15 (Tabel 5).

Lama perawatan pasien yang meninggal berhubungan dengan derajat keparahan pasien. Lama perawatan semakin meningkat seiring dengan peningkatan kelompok interval yang mencapai puncak pada kelompok interval 25-29, yaitu berjumlah 15,53 hari. Lama perawatan menurun sedikit pada kelompok interval 30-34, yaitu 13,5 hari (Tabel 6).

Peneliti juga meneliti pasien bedah saraf emergensi yang meninggal sesuai kelompok interval skor APACHE II sebagai temuan lain. Hasilnya adalah terdapat 19 pasien cedera kepala emergensi dengan skor APACHE II 16-24. Mortalitas kelompok pasien ini adalah 13 pasien, yaitu 18,6\% dari total pasien kelompok interval 16-24 yang meninggal. Pasien itu terdiri atas cedera kepala berat hingga moderat. 
Tabel 2 Skor APACHE II di ICU RSUP Dr. Hasan Sadikin Bandung

\begin{tabular}{lccc}
\hline \multirow{2}{*}{ Skor APACHE II } & \multicolumn{2}{c}{ Kelompok } & \multirow{2}{*}{ Total } \\
\cline { 2 - 3 } & $\begin{array}{c}\text { Meninggal } \\
\mathbf{n = 1 3 0}\end{array}$ & $\begin{array}{c}\text { Pindah Ruangan } \\
\mathbf{n = 1 7 3}\end{array}$ & \\
\hline Mean \pm Std & $19,69 \pm 7,165$ & $14,42 \pm 6,592$ & $16,68 \pm 7,31$ \\
Median & 19,00 & 14,00 & 16,00 \\
Range (min.-maks.) & $6,00-56,00$ & $0,00-33,00$ & $0,00-56,00$ \\
\hline
\end{tabular}

Tabel 3 Gambaran lama perawatan di ICU RSUP Dr. Hasan Sadikin

\begin{tabular}{lccc}
\hline \multirow{2}{*}{ Lama Perawatan (hari) } & \multicolumn{2}{c}{ Kelompok } & \multirow{2}{*}{ Total } \\
\cline { 2 - 3 } & $\begin{array}{c}\text { Meninggal } \\
\mathbf{n = 1 3 0}\end{array}$ & $\begin{array}{c}\text { Pindah Ruangan } \\
\mathbf{n = 1 7 3}\end{array}$ & \\
\hline Mean \pm Std & $9,33 \pm 12.714$ & $10,68 \pm 12.821$ & $9,89 \pm 12.473$ \\
Median & 5 & 5 & 5 \\
Range (min.-maks.) & $2,00-98,00$ & $2,00-79,00$ & $2,00-98,00$ \\
\hline
\end{tabular}

\section{Pembahasan}

Pasien penyakit kritis mengalami kegagalan perfusi dan kegagalan fungsi organ yang berbeda. Hal ini menyebabkan derajat keparahan penyakit yang berbeda-beda pula. Derajat keparahan penyakit dapat diukur salah satunya dengan skor APACHE II. Skor APACHE II, lama perawatan, dan angka mortalitas merupakan indikator-indikator penting pada perawatan di ICU.

Nilai rerata skor APACHE II di ICU RSUP Dr. Hasan Sadikin Bandung adalah 16,68. Data ini masih jauh lebih tinggi di atas Amerika Serikat dan Selandia Baru (berturut-turut 10,7 dan
14,2). ${ }^{1}$ Data ini hampir sama bila dibanding dengan data dari Brazil. Skor APACHE II rerata di rumah sakit pendidikan di Brazil adalah 18,6 untuk pasien bedah nonelektif. Tingginya skor rerata APACHE II pada pasien bedah nonelektif dapat disebabkan oleh tingginya derajat keparahan pasien pada pasien nonelektif. ${ }^{6,7}$ Pasien-pasien ini biasanya masuk melalui IGD dengan kondisi gawat darurat dan mengancam nyawa. Salah satu hal yang membuat perbedaan ini adalah banyaknya pasien bedah nonelektif di ICU RSUP Dr. Hasan Sadikin Bandung. Pasien bedah nonelektif memengaruhi rerata skor APACHE II sehingga semakin tinggi pasien bedah nonelektif

Tabel 4 Gambaran angka mortalitas ICU RSUP Dr. Hasan Sadikin, Bandung

\begin{tabular}{cccc}
\hline Skor Apache Ii & Jumlah Pasien & $\begin{array}{c}\text { Jumlah Pasien } \\
\text { Meninggal }\end{array}$ & Mortalitas Aktual \\
\hline $0-4$ & 7 & 0 & $0,0 \%$ \\
$5-9$ & 39 & 5 & $12,8 \%$ \\
$10-14$ & 73 & 26 & $35,1 \%$ \\
$15-19$ & 77 & 35 & $45,5 \%$ \\
$20-24$ & 65 & 35 & $53,8 \%$ \\
$25-29$ & 25 & 14 & $56,0 \%$ \\
$30-34$ & 15 & 11 & $73,3 \%$ \\
$>34$ & 2 & 2 & $100,0 \%$ \\
\hline
\end{tabular}


Tabel 5 Tabel Gambaran Skor APACHE II dengan Asal Admisi

\begin{tabular}{|c|c|c|c|c|c|c|}
\hline \multirow[b]{2}{*}{ Skor APACHE II } & \multicolumn{3}{|c|}{ Kelompok Emergensi } & \multicolumn{3}{|c|}{ Kelompok Ruang Rawat } \\
\hline & $\begin{array}{c}\text { Meninggal } \\
n=40\end{array}$ & $\begin{array}{c}\text { Pindah } \\
\text { Ruangan } \\
n=51\end{array}$ & Total & $\begin{array}{c}\text { Meninggal } \\
n=90\end{array}$ & $\begin{array}{c}\text { Pindah } \\
\text { Ruangan } \\
\text { n=122 }\end{array}$ & Total \\
\hline Mean \pm Std & $20,25 \pm 7,999$ & $16,07 \pm 6,802$ & 17,91 & $19,44 \pm 6,795$ & $13,72 \pm 6,405$ & 16,15 \\
\hline Median & 19,00 & 15,00 & & 19,00 & 13,00 & \\
\hline Range (min.-maks.) & $8,00-56,00$ & $2,00-33,00$ & & $6,00-36,00$ & $0,00-33,00$ & \\
\hline
\end{tabular}

semakin tinggi pula rerata skor APACHE II. ${ }^{1,6,7}$

Data skor APACHE II rerata yang dibandingkan dengan luaran pasien, menunjukkan skor APACHE II rerata 19,56 pada pasien yang meninggal selama perawatan dan 14,42 pada pasien yang pindah ruangan selama perawatan. Hal ini sesuai dengan penelitian lain bahwa skor APACHE II menentukan derajat keparahan penyakit. Pasien yang meninggal mempunyai derajat keparahan pasien lebih tinggi dibanding dengan pasien yang pindah ruangan. ${ }^{1,6-8}$

Data skor APACHE II rerata yang dibanding dengan asal admisi menunjukkan skor APACHE II rerata 17,91 pada pasien dari IGD dan 16,19 pada pasien dari ruang rawat. Skor rerata APACHE II dari ruangan hampir sama dengan skor rerata APACHE II dari IGD. Skor APACHE II rerata yang tinggi dari ruang rawat menggambarkan kondisi pasien yang jelek sebelum masuk ICU. Hal ini dapat menggambarkan kurang efektifnya sistem early warning score (EWS) di ruangan. Intervensi yang baik pada pasien yang mengalami emergensi medik di ruangan dan monitoring ketat pada pasien yang menunjukkan gejala emergensi medik secara dini akan menurunkan skor rerata APACHE II pada pasien ICU dengan asal admisi ruangan. ${ }^{9}$

Rerata lama perawatan di ICU RSUP Dr. Hasan Sadikin Bandung adalah 9,89 hari. Faktor yang memengaruhi lama perawatan adalah faktor institusi, faktor medis, faktor sosial, dan faktor psikologis. ${ }^{10}$ Di ICU RSUP Dr. Hasan Sadikin Bandung, faktor institusi dapat memengaruhi lama perawatan karena setiap institusi mempunyai aturan, standar prosedur operasional, dan pengaruh politis yang berbeda satu sama lain. Lama perawatan di ICU RSUP Dr. Hasan Sadikin Bandung juga dipengaruhi oleh faktor medis. Faktor-faktor medis adalah: derajat keparahan penyakit, pasien yang sudah pernah keluar ICU, namun masuk lagi karena perburukan, lama

Tabel 6 Gambaran Skor APACHE II dengan Rerata Lama Perawatan

\begin{tabular}{|c|c|c|c|c|c|}
\hline \multirow{3}{*}{ Skor APACHE II } & \multicolumn{4}{|c|}{ Rata-rata Lama Perawatan } & \multirow{3}{*}{$\begin{array}{c}\text { Rerata Lama } \\
\text { Perawatan Total (Hari) }\end{array}$} \\
\hline & \multicolumn{2}{|c|}{$\begin{array}{c}\text { Meninggal } \\
n=130\end{array}$} & \multicolumn{2}{|c|}{$\begin{array}{c}\text { Pindah Ruangan } \\
\mathbf{n}=\mathbf{1 7 3}\end{array}$} & \\
\hline & Jumlah & Rerata (Hari) & Jumlah & Rerata (Hari) & \\
\hline $0-4$ & 0 & 0,00 & 6 & 4,83 & 4,83 \\
\hline $5-9$ & 5 & 13,4 & 36 & 7,08 & 7,85 \\
\hline $10-14$ & 25 & 14,44 & 45 & 9,4 & 11,2 \\
\hline $15-19$ & 35 & 9,31 & 41 & 12,56 & 11,06 \\
\hline $20-24$ & 35 & 7,8 & 28 & 13,80 & 10,38 \\
\hline $25-29$ & 12 & 6,54 & 13 & 15,53 & 11,21 \\
\hline $30-34$ & 13 & 4,81 & 2 & 13,5 & 5,97 \\
\hline$>34$ & 2 & 4,5 & 0 & 0,00 & 4,5 \\
\hline
\end{tabular}


perawatan pra-ICU, serta angka kejadian HAP dan VAP. ${ }^{4,10-13}$ Lama perawatan di ICU RSUP Dr. Hasan Sadikin Bandung juga dipengaruhi oleh faktor sosial, seperti komunikasi yang efektif dan faktor psikologis keluarga. Keluarga pasien yang dirawat di ICU RSUP Dr. Hasan Sadikin Bandung merupakan keluarga besar (extended family). Keputusan diambil bersama. Hal ini yang dapat meningkatkan lama perawatan.

Faktor medis yang banyak berperan pada lama perawatan di ICU RSUP Dr. Hasan Sadikin Bandung adalah derajat keparahan pasien yang dinilai oleh skor APACHE II. Data skor APACHE II berdasar atas lama perawatan menunjukkan gambaran bell-shaped (Tabel 6). Pada lama perawatan total tampak lama perawatan meningkat seiring dengan peningkatan skor APACHE II hingga satu poin seiring dengan peningkatan skor APACHE II lama perawatan menurun. Hal ini dikarenakan pasien derajat keparahan penyakit yang ringan dan berat mempunyai lama perawatan yang singkat. Pasien pada kelompok interval ini mempunyai angka kesembuhan yang tinggi sehingga dapat pindah ruangan ataupun mempunyai angka mortalitas yang tinggi sehingga cepat meninggal. ${ }^{5}$

Data luaran pasien berdasar atas kelompok interval skor APACHE II di ICU RSUP Dr. Hasan Sadikin Bandung masih lebih tinggi dibanding dengan Amerika Serikat. Ada beberapa faktor yang dapat berperan pada perbedaan kedua data ini, yaitu perbedaan geografis dan institusional, underestimation derajat keparahan pasien cedera kepala, bias yang ditimbulkan dari intervensi pra-ICU, dan gangguan organ utama yang timbul lebih dari 24 jam.

Skor APACHE II dibuat dan divalidasi pertama kali pada 5.815 pasien yang masuk ke ICU dari 13 rumah sakit di Amerika Serikat. Perbedaan geografis, tipe penyakit, aturan institusi, kelengkapan sumber daya dan sumber daya manusia dapat membuat prediksi angka mortalitas yang berbeda di ICU RSUP Dr. Hasan Sadikin Bandung. ${ }^{8}$ Pakistan dan Brazil juga menunjukkan angka mortalitas yang berbeda dari Amerika Serikat sesuai dengan keadaan negara mereka. Pada prinsipnya data dari Pakistan dan Brazil juga menunjukkan angka mortalitas yang meningkat seiring dengan peningkatan skor APACHE II, namun prediksi angka mortalitas tiap kelompok interval juga berbeda dengan Amerika Serikat. ${ }^{1,6}$ Oleh karena itu, validasi yang merata dengan banyak sampel pada banyak ICU di Indonesia dibutuhkan untuk membuat angka mortalitas prediksi yang dapat dijadikan acuan di Indonesia.

Skor APACHE II menunjukkan underestimation derajat keparahan pasien dengan cedera kepala. Satu penelitian menunjukkan skor APACHE II rerata pada pasien cedera kepala yang meninggal di ICU tidak pernah sesuai dengan angka mortalitas prediksi. Hal ini dikarenakan sebagian besar pasien ini berusia $<45$ tahun dengan nilai variabel skor APACHE II yang normal sehingga terjadi underestimation derajat keparahan pasien. Mortalitas pasien menjadi tidak sesuai dengan prediksi kematian menurut skor APACHE II. ${ }^{14}$ Mortalitas pasien cedera kepala di ICU RSUP Dr. Hasan Sadikin Bandung adalah $18,6 \%$ dari total pasien kelompok interval 16-24 yang meninggal. Angka ini dapat menyebabkan underestimation seperti yang dilaporkan penelitian oleh Meyer dan menyebabkan peningkatan angka mortalitas pasien dengan skor APACHE II 16-24.

Salah satu faktor yang memengaruhi skor APACHE II dalam 24 jam pertama masuk ICU adalah penanganan pasien sebelum masuk ICU. Skor APACHE II tidak menilai tindakan resusitasi yang dilakukan sebelum masuk ke ICU sehingga skor APACHE II yang diukur dapat menjadi under- atau overestimation dari keadaan pasien yang sebenarnya. ${ }^{15}$ Pengecekan skor APACHE II di ICU RSUP Dr. Hasan Sadikin Bandung dilakukan dalam kurun waktu 24 jam, namun sebagian besar mengambil variabel setelah dilakukan resusitasi di ruang resusitasi. Skor APACHE II akan sangat berbeda setelah dilakukan resusitasi. Hal ini berpotensi menyebabkan bias dan underestimation skor APACHE II. ${ }^{15,16}$

Mucart dkk. ${ }^{16,17}$ mengemukakan gangguan organ yang utama mungkin dapat timbul lebih dari 24 jam. Hal ini menimbulkan 
ketidaksesuaian angka mortalitas karena skor APACHE II hanya mengukur dalam 24 jam pertama. Keterbatasan penelitian ini adalah banyak skor APACHE II yang tidak tertulis di status flow chart pasien sehingga harus dilakukan penghitungan ulang skor APACHE II sampel penelitian.

\section{Simpulan}

Pasien yang dirawat di ICU RSUP Dr. Hasan Sadikin, Bandung periode 1 Januari hingga 31 Desember 2017 mempunyai skor APACHE II rerata 16,68 dengan nilai terendah 0 dan nilai tertinggi 56. Angka mortalitas 130 pasien $(42,2 \%)$, lama perawatan rerata 9,89 hari, lama perawatan tercepat 2 hari, dan lama perawatan terlama 79 hari.

\section{Daftar Pustaka}

1. Naved SA, Siddiqui S, Khan FH. APACHEII score correlation with mortality and length of stay in an intensive care unit. J Coll Physicians Surg Pak. 2011;21(1):4-8.

2. Bouch C, Thompson J. Severity scoring systems in the critically ill. Cont Edu Anaest Crit Care Pain. 2008;8:181-5.

3. Knaus WA, Wagner DP, Draper EA, Zimmerman JE, Bergner M, Bastos PG, dkk. The APACHE III prognostic system. Chest. 1985;100(6):1619-36.

4. Almashrafi A, Elmontsri M, Aylin P. Systematic review of factors influencing length of stay in ICU after adult cardiac surgery. BMC Health Serv Res. 2016;16:1-12.

5. Arabi Y, Venkatesh S, Haddad S, AlShimemeri A, Al-Malik S. A prospective study of prolonged stay in the intensive care unit: predictor and impact on resource utilization. Int J Qual Health Care. 2002;14:403-10.

6. Chiavone PA, Santos-Sens YAd. Evaluation of APACHE II system among intensive care patients at a teaching hospital. San Paolo Med J. 2003;121(2):53-7.

7. Coelho-D'Costa VE, Spiro P, Dartey-Hayford $\mathrm{S}$, Iqbal J. Evaluation of the APACHE II scoring system and hospital outcome in an inner city hospital intensive care unit. Chest. 2004;126(4):21-2.

8. Knaus WA, Draper EA, Wagner DP, Zimmerman JE. APACHE II: a severity of disease classification systme. Crit Care Med. 1985;13:818-29.

9. Nishijima I, Oyadomari S, Maedomari S, Toma R, Igei C, Kobata S, dkk. Use of a modified early warning score system to reduce the rate of in-hospital cardiac arrest. J Intensive Care Med. 2016;4(12):1-6.

10. Gruenberg D, Shelton W, Rose S, Rutter A, Socaris S, McGee G. Factors influencing length of stay in the intensive care unit. Am J Crit Care. 2006;15:502-9.

11. Arabi Y, Haddad S, Shirawi N, Al-Shimemeri A. Early tracheostomy in intensive care trauma patients improves resource utilization: a cohort study and literature review. Crit Care. 2004;8(47):347-52.

12. Higgins TL, McGee WT, Steingrub JS, Rapoport J, Lemeshow S, Teres D. Early indicators of prolonged intensive care unit stay: impact of illness severity, physician staffing, and pre-intensive care unit length of stay. Crit Care Med. 2003;31:45-51.

13. Hunter A, Johnson L, Coustasse A. Reduction of intensive care unit length of stay: the case of early mobilization. Health Care Manager. 2014;33:128-35.

14. Meyer AA, Messick WJ, Young P, Baker CC, Fakhry S, Muakkassa F, dkk. Prospective comparison of clinical judgement and APACHE II score in predicting the outcome in critically ill surgical patients. J Trauma. 1992;32(6):747-54.

15. Cowen JS, Kelley MA. Errors and bias in using predictive scoring system. Crit Care Clin. 1994;10(1):53-72.

16. Muckart DJJ, Bhagwanjee S, Neijenhuis PA. Prediction of the risk of death by APACHE II scoring in critically ill trauma patients without head injury. Br J Surg. 1996;83(1):1123-7.

17. Muckart DJJ, Thomson SR. Undetected injuries: A preventable cause of increase morbidity and mortality. Am J Surg. 1991;162:457-60. 